\title{
Time-resolved porosity changes at cement-clay interfaces derived from neutron imaging
}

\author{
Shafizadeh A. ${ }^{a}$, Gimmi T. ${ }^{\mathrm{a}, \mathrm{c}, *}$, Van Loon L.R. ${ }^{\mathrm{a}}$, Kaestner A.P. ${ }^{\mathrm{b}}$, Mäder U.K. ${ }^{\mathrm{c}}$, \\ Churakov S.V. ${ }^{\mathrm{a}, \mathrm{c}}$ \\ ${ }^{a}$ Laboratory for Waste Management, Paul Scherrer Institut, 5232 Villigen PSI, Switzerland \\ ${ }^{b}$ Laboratory for Neutron Scattering and Imaging, Paul Scherrer Institut, 5232 Villigen PSI, \\ Switzerland \\ ${ }^{c}$ Institute of Geology, University of Bern, 3012 Bern, Switzerland
}

\begin{abstract}
Interfaces between cement and clay are common in engineered barrier systems for the underground disposal of radioactive waste. The geochemical contrast between clay and cement leads to alterations of both materials following dissolution and precipitation reactions. Porosity is a key parameter for, and a key outcome of, such reactive transport. Here we report on the evolution of porosity within small samples made from ordinary portland cement and $\mathrm{Na}$ montmorillonite. Water contents, a proxy for porosity in saturated samples, were derived from neutron imaging. Specific calibration procedures were developed to account for multiple scattering effects. An increase in cement porosity was observed propagating $\sim 2 \mathrm{~mm}$ away from the interface within 600 days, and a considerable decrease in clay porosity within $\sim 2 \mathrm{~mm}$. Our experiments provide unique information on the dynamics of the processes up to nearly two years. The data set provides valuable input to better constrain reactive transport models.

Keywords: neutron imaging, cement-clay interaction, radioactive waste (E), porosity, water content, reactive transport, image analysis (B), interfacial transition zone (B), transport properties $(\mathrm{C})$, cement paste $(\mathrm{D})$, portland cement (D), waste management (E)
\end{abstract}

\footnotetext{
${ }^{*}$ Corresponding author

Email address: thomas.gimmi@geo.unibe.ch, thomas.gimmi@psi.ch (Gimmi T.)
}

Preprint submitted to Cement and Concrete Research

October 1, 2019 


\section{Introduction}

3

Cement and clay are two key components of the barrier systems of radioactive waste repositories. In the multi-barrier design of such repositories, intended to mechanically reinforce open galleries and to enclose waste canisters, large amounts of cementitious material will be used in direct contact with the clay formations or with clays of the engineered barrier systems (EBS). One of the factors affecting the EBS performance is the long-term development of the contact zone between cement and clay. Differences in chemical compositions between these two materials cause diffusive mass flux across their interface, possibly followed by mineral dissolution and precipitation reactions which will alter the composition and structure of both materials.

Several laboratory and field experiments [e.g., 1-11] as well as evidences from natural analogues [e.g., 12 provide information on possible alterations at the material interfaces. For instance, the cement-clay interaction (CI) field experiment in the Mont Terri rock laboratory was initialized to investigate interactions between Opalinus Clay and various types of concretes and cements [2 4]. Alterations within clay or cement matrix were investigated with various techniques. The presence of aggregate grains within the concrete made the application of these techniques difficult, but it was possible to delineate various reaction zones based on SEM/EDX element mapping and XRD measurements. Porosity values derived from impregnation with a traced resin followed by autoradiography were reported by Jenni et al. 2]. They reported a reduction in porosity in the first $\sim 1 \mathrm{~mm}$ of cement compared to the cement porosity further away, which they related to carbonation. Porosities in both cement regions were, however, larger than expected based on the used water to cement ratio.

Autoradiography and petrophysical measurements of Gaboreau et al. [7 on cement-clay interface samples from the Tournemire underground research laboratory (France) after 15 years of interaction showed a clogging of the porosity in the claystone, likely due to precipitation of secondary phases (e.g., C-S-H), and a porosity increase in the cement. They observed heterogeneous zones of 
the porosity evolution on both sides of the interface, with extents on the order of centimeters $(3.5 \mathrm{~cm}$ in the cement and $1.5-2 \mathrm{~cm}$ in the claystone). In another study at the same location, Techer et al. 8] confirmed a limited spatial extent of the interactions in the clay-rich rock, with the alteration extending over a few centimeters. In an experiment, also at the Tournemire site, Lalan et al. [10, 11] contacted ordinary portlandite heated to $70^{\circ} \mathrm{C}$ for one year with the argillite. They found a decrease of porosity on both sides of the interface.

Cruz Alonso et al. [5] and Fernández et al. 6] reported on the interaction of concrete with bentonite in the FEBEX experiment at the Grimsel Test Site. After 13 years of interaction, pronounced changes were observed within the first centimeter of a concrete plug in contact with bentonite. The complete disappearance of portlandite in this first centimeter was noted along with a massive ettringite formation, with the sulfate very likely originating from the bentonite. A limited impact on the bulk mineralogy was found on the clay side, with only small changes (some dissolution of primary minerals and some precipitation of secondary minerals) in the first few millimeters, but a somewhat more extended redistribution of exchangeable cations.

Various numerical studies were performed to predict mineral alteration pathways when cementitious material interacts with clay. In a study on the interaction of cement with different clay host rocks, Kosakowski and Berner [13] estimated for instance the extents of alteration zones for different transport scenarios in a set of long-term predictive calculations. After $\sim 2000$ years, the alterations were limited to a comparably narrow zone around the interface $(<5$ $\mathrm{cm}$ ), with the porosity tending to zero in the clay, which stopped a further development in the diffusive transport scenario. In another numerical study, Traber and Mäder [14] obtained an altered zone at an Opalinus Clay-concrete interface with an extent of less than $20 \mathrm{~cm}$. The uncertainties of numerical studies are rather large, among other things because kinetic reaction rates and the feedback of mineral alterations on the further diffusive transport are largely unknown [15, 16].

Even though clogging might eventually be favorable to delay the migration 
of radionuclides to the surrounding clay formation, it may have a negative effect on the re-saturation of the clay formation after closure of a repository, reducing its chemical and mechanical buffer capacity as well as the overall functionality of the repository. It could also impact the release of gases at a later stage. Developing methodologies to provide experimental data on these alterations and their coupled feedback on the repository's transport processes at different time scales is an essential task in order to refine the current assumptions used in predictive transport simulations and to increase the reliability of these predictions. Porosity is a central input parameter in reactive transport models, but also a central outcome. Accordingly, knowing its evolution with time is particularly important.

Within the scope of the present study, a laboratory experiment has been designed and performed to investigate the above mentioned alterations under well controlled conditions, in a non-destructive way, and over a time period of months to several years. The experimental cell design makes it possible to benefit from a broad range of non-destructive analyses. Here we present the results from the first three years of monitoring of water contents at an ordinary portland cement (OPC) - Na-montmorillonite interface as obtained from neutron imaging.

\section{Materials and methods}

\subsection{Sample preparation}

The samples of hardened OPC paste, with $5 \mathrm{~mm}$ diameter and about 5 mm length, were drilled out of a 14 years old CEM I 52.5 N HTS plug, which was prepared in 2001 [17 20], then stored in a sealed container and, before sample preparation, brought into contact with the artificial cement pore water, as described by Tits et al. [19. For the clay samples, a conditioned Namontmorillonite powder [21] was used. The powder was pre-saturated within a

desiccator that contained humid air, then compacted to the final $5 \mathrm{~mm}$ diameter 
and $5 \mathrm{~mm}$ length in a compaction cell. Details on the origin of the material are given in Shafizadeh et al. 22, including the chemical compositions.

The cement and clay plugs were then brought into direct contact in the diffusion cell designed to host the samples and at the same time to allow in-situ experimental techniques to be applied (Fig. 1). In detail, the samples were first introduced into the inert PTFE holders which was then inserted in the aluminum cell. The PEEK porous filters were added to both sides. The two PEEK end caps (screwed to the aluminum body) kept the samples, the PTFE and the filters in place while providing a connection to an external fluid reservoir. Cell type II was designed after the first measurement campaign with cell type I. The improved cell design led to a better signal to noise ratio and caused less artifacts in neutron radiographs, owing to the thinner aluminum part and the elimination of interfering joints. The cell geometry was also changed to a cylindrical shape for future tomography measurements. Also, the new cell has a smaller outer dimension compared to type I and thus allows for having an open beam section within the image, which lowers the uncertainty in data evaluation.

Table 1 summarizes the cement-clay interface samples prepared for this study as well as the properties of both cement and clay materials, prior to their contact. Samples were kept in the diffusion cell while the left and right ends were in contact with the corresponding pore water solutions. A peristaltic pump was used to continuously circulate the solution between sample and reservoir. The samples were kept in a glove box environment to avoid $\mathrm{CO}_{2}$ contaminations and carbonation of the cement. The corresponding pore water compositions for the OPC and the Na-montmorillonite are reported in Table 2 .

For the neutron radiography measurements, the cells were disconnected from the pump and the solution reservoir, and openings were closed with dead end screws to ensures the cell tightness.

\subsection{Neutron imaging measurements}

The high interaction probability of neutrons with hydrogenous compounds makes neutron imaging a powerful non-destructive technique to study water dis- 

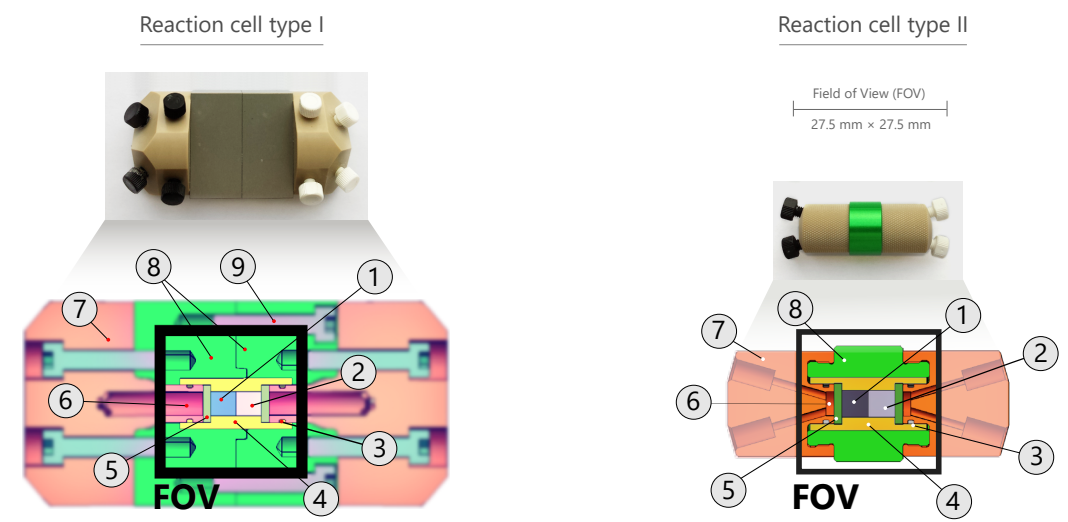

Figure 1: The two designs of the reaction cells used in this study. The components of both reaction cells are (1) Cement sample, (2) clay sample, (3) O-rings, (4) PTFE sample holder, (5) PEEK frits, (6) solution reservoirs within PEEK caps, (7) PEEK caps, (8) aluminum holder and (9) screws. The black square shows the field of view (FOV, $27.5 \mathrm{~mm}$ x $27.5 \mathrm{~mm}$ ) for the neutron images. Outer cell dimensions (without screws): $83 \mathrm{~mm}$ x $40 \mathrm{~mm}$ x $25 \mathrm{~mm}$ (type I), $53 \mathrm{~mm} \times 22 \mathrm{~mm} \varnothing$ (type II)

tribution inside porous materials 24]. At present, it allows measurements with a spatial resolution down to $\sim 10 \mu \mathrm{m}$ and a temporal resolution of minutes to hours $24-32$. Neutron radiography measurements of the cement-clay interface samples were performed at the ICON beamline (Imaging with Cold Neutrons) at the Paul Scherrer Institut (PSI) 33. Technical specifications of the measurements have been given earlier in Shafizadeh et al. 22. The prepared interface samples were radiographed at different times in order to obtain the evolution of water content profiles across the interface.

The neutron beam is collimated from the Swiss spallation neutron source (SINQ, PSI) through vacuum flight tubes towards the sample (collimation ratio $343 \mathrm{~m} / \mathrm{m}$ ). Once it reaches the sample, it can be transmitted through the sample or interact with it, which results in attenuation. This attenuation happens when neutrons are absorbed or scattered by the nuclei of the atoms. The transmitted neutrons hit a Gd-based scintillator (with $20 \mu \mathrm{m}$ thickness) with a total field of 
Table 1: Overview on the properties of the interface samples used in this study.

\begin{tabular}{|c|c|c|c|c|c|c|c|}
\hline \multirow[b]{2}{*}{ Cell } & \multicolumn{3}{|c|}{ Clay } & \multicolumn{3}{|c|}{ Cement } & \multirow{5}{*}{$\begin{array}{l}\text { Interface } \\
\text { contact } \\
\text { date }\end{array}$} \\
\hline & Dry & Porosity $^{a}$ & Length & Dry & Porosity & Length & \\
\hline No. & bulk & & & bulk & & & \\
\hline & density & & & density & & & \\
\hline$(-)$ & $\left(\mathrm{g} \mathrm{cm}^{-3}\right)$ & $\left(\mathrm{m}^{3} \mathrm{~m}^{-3}\right)$ & $(\mathrm{mm})$ & $\left(\mathrm{g} \mathrm{cm}^{-3}\right)$ & $\left(\mathrm{m}^{3} \mathrm{~m}^{-3}\right)$ & $(\mathrm{mm})$ & \\
\hline C1 & 1.67 & 0.39 & 5.5 & 0.77 & 0.63 & 4.5 & 14.03 .2013 \\
\hline C5 & 1.44 & 0.49 & 5.1 & 0.77 & 0.63 & 4.9 & 25.09 .2013 \\
\hline
\end{tabular}

${ }^{a}$ From dry bulk density with grain density of $2.76 \mathrm{~g} \mathrm{~cm}^{-3}$ (C1) and $2.8 \mathrm{~g} \mathrm{~cm}^{-3}$ (C5)

Common parameters:

Sample diameter is $5 \mathrm{~mm}$

Cement initial pore water $\mathrm{pH}$ is 13.3 [19] and clay initial pore water $\mathrm{pH}$ is 8.7

view of $27 \times 27 \mathrm{~mm}^{2}$. The scintillator converts the neutron signals into visible light photons. The photons are then guided via a mirror and a lens system to the cooled CCD camera (with $2048 \times 2048$ pixels), where they are digitally recorded and displayed as a 16-bit gray value image. The exposure time of $90 \mathrm{~s}$ was needed to obtain a sufficiently high signal to noise ratio to allow a quantitative analysis of the image data. It is also important in order to reach the highest possible resolution which is reported to be $27 \mu \mathrm{m} \times 27 \mu \mathrm{m}$ [33]. In own independent test measurements with the Siemens star periods around $50 \mu \mathrm{m}$ could be resolved. The obtained gray value images were corrected (flat field, dark noise, dose, geometry, 22] and Appendix C) and then processed to obtain water content profiles across the interface sample.

The physical relation between the incident neutron beam $I_{0}$ and transmitted neutrons $I_{T}$ is described by the Beer-Lambert law,

$$
\frac{I_{T}}{I_{0}}=\mathrm{e}^{-\sum_{i=1}^{n} \mu_{i} d_{i}}
$$

where $\mu_{i}$ is the attenuation coefficient of each individual material present in the 
Table 2: Aqueous total concentrations, $\mathrm{OH}^{-}$concentrations, $\mathrm{pH}$, and ionic strength (IS) of pore waters in OPC and montmorillonite, calculated by GEMS 23.

\begin{tabular}{llll}
\hline & OPC & Initial gradient & Montmorillonite \\
& $\left(\mathrm{mol} \mathrm{L}^{-1}\right)$ & & $\left(\mathrm{mol} \mathrm{L}^{-1}\right)$ \\
\hline $\mathrm{Na}$ & 0.11 & $\longleftrightarrow$ & 0.30 \\
$\mathrm{~K}$ & 0.21 & $\longrightarrow$ & - \\
$\mathrm{Ca}$ & 0.023 & $\longleftarrow$ & $1.0 \times 10^{-6}$ \\
$\mathrm{Mg}$ & $1.0 \times 10^{-6}$ & $\longrightarrow$ & - \\
$\mathrm{C}^{\mathrm{IV}}$ & $1.1 \times 10^{-4}$ & & - \\
$\mathrm{Cl}$ & $1.7 \times 10^{-5}$ & $\longleftarrow$ & 0.30 \\
$\mathrm{~S}^{\mathrm{VI}}$ & - & $\longleftarrow$ & 0.019 \\
$\mathrm{OH}$ & & & $5.1 \times 10^{-6}$ \\
$\mathrm{pH}$ & 0.306 & & 8.7 \\
$\mathrm{IS}$ & 13.3 & & 0.3 \\
\hline
\end{tabular}


sample and $d_{i}$ the distance that a beam travels through that material. The attenuation coefficient $\mu$ of a material is a measure of how strong neutrons interact with the matter. The high attenuation coefficient of hydrogen atoms (present mainly in water), relative to other elements in our samples, makes neutron attenuation most sensitive to the amount of pore water in the cementclay interface samples.

Ideally, the thickness of an individual material (e.g., $d_{w}$ of water) in a sample composed of several different materials can be calculated from Eq. 1 with known $\mu_{i}$ and thicknesses $d_{i \neq w}$ of all other materials. The contribution of all other materials can be obtained from the image $I_{T, d r y} / I_{0, d r y}$ of the dry sample, leading to:

$$
d_{w}=-\frac{1}{\mu_{w}}\left(\ln \left[\frac{I_{T}}{I_{0}} / \frac{I_{T, d r y}}{I_{0, d r y}}\right]\right) .
$$

The water content $\theta$ is then given as $\theta=d_{w} / d_{T}$, where $d_{T}$ is the total thickness of the sample. In reality, however, obtaining an image of the dry sample may not be feasible, and the attenuation of neutrons through water is not fully linear, making calibration not so simple. The details of our calibration procedure are given in the next subsection.

\subsection{Calibration procedure}

As our samples had to remain saturated throughout the whole experiment, the reference image of the dry sample was synthesized from separate image parts with a dried cement and a dried clay [22. This introduces additional uncertainty especially with respect to single pixel values, but the following calibration can compensate for a possible average bias. To derive the $2 \mathrm{D}$ water content field in a radiograph, first the cylindrical geometry (variable $d_{T}$ ) had to be taken into account according to $d_{T}(y)=2 \sqrt{2 y r-y^{2}}$, where $r$ is the radius of the sample and $y$ the lateral position in the radiograph with the sample extending from $y=0$ to $y=2 r$ (Fig. 2). Then, the water attenuation coefficient $\left(\mu_{w}\right)$ is needed. This $2 \mathrm{D}$ matrix can be obtained in principle from the theoretical values for hydrogen and oxygen at the beam energy peak of the ICON instrument; 
or, by performing a calibration measurement with pure water. Both of these methods provide a single value for $\mu_{w}$ but result in water contents that are not matching with true water contents of our samples (measured for the cement and calculated from the bulk density for the clay). Therefore, the contribution of multiple scattering on the recorded radiographs as well as other image artefacts need to be corrected for in a more detailed manner.

From calibration measurements with pure water (Fig. A.1 a,b in the appendix), we observed that the effective attenuation coefficient $\mu_{w}$ decreased with increasing sample thickness, which coincides here with increasing distance from the lateral boundaries of the sample (Fig. A.1F) due to multiple scattering [34. Whereas using a single value for $\mu_{w}$ will cause both under- and over-estimation of water contents (Fig. A.1 , the green and red lines) in some regions of the sample, a linear relation

$$
\mu_{w, \mathrm{eff}}=\mu_{0}+\beta d_{w}
$$

(Fig. A.1k, the blue line) will provide correct water contents in the sample (Fig. A.1d, the dashed line). Using such a linear relation in Eq. 2 allows then estimating the water content from $\mu_{0}$ and $\beta$ according to

$$
\theta=\frac{d_{w}}{d_{T}}=-\frac{1}{d_{T}}\left[\left(\frac{\mu_{0}}{2 \beta}\right)+\sqrt{\left(\frac{\mu_{0}}{2 \beta}\right)^{2}+\frac{1}{\beta} \ln \left[\frac{T_{d r y}}{T}\right]} .\right]
$$

It is clear that the empirical linear relation for $\mu_{w}$ will be only approximately correct for cylindrical samples, even if they have homogeneous water contents within their circular cross section, because effects of multiple scattering depend not only on the local amount (thickness) of water but also on the distance between sample and detector 34, which is a function of $y$ for cylindrical samples. Nevertheless, this approximate correction works well for samples of our size having radially homogeneous water content, as was demonstrated for the pure water sample. Accordingly, we expect it to lead to good results also for our clay-cement samples, where no (or no large) radial gradients in water content are expected.

In Shafizadeh et al. 22, it was suggested to use two internal parts of the 
sample, denoted as 1 and 2 , with known water contents $\theta_{1}$ and $\theta_{2}$ (e.g., one in clay and one in cement) to derive the two required calibration parameters $\mu_{0}$ and $\beta$ in Eq. 4. By substituting known $\theta_{1}$ and $\theta_{2}, d_{T_{1}}$ and $d_{T_{2}}$ from sample geometry, and $A_{1}$ and $A_{2}$ from the neutron radiographs where $A_{i}=\ln \left[\frac{T_{d r y}}{T_{i}}\right]$, Eq. 4 can be solved for $\mu_{0}$ and $\beta$,

$$
\begin{aligned}
& \mu_{0}=\frac{A_{2} \cdot \theta_{1}{ }^{2} \cdot d_{T_{1}}{ }^{2}-A_{1} \cdot \theta_{2}{ }^{2} \cdot d_{T_{2}}{ }^{2}}{d_{T_{1}} \cdot d_{T_{2}} \cdot \theta_{1} \cdot \theta_{2}\left(d_{T_{1}} \cdot \theta_{1}-d_{T_{2}} \cdot \theta_{2}\right)} \\
& \beta=\frac{-A_{2} \cdot \theta_{1} d_{T_{1}}+A_{1} \cdot \theta_{2} d_{T_{2}}}{d_{T_{1}} \cdot d_{T_{2}} \cdot \theta_{1} \cdot \theta_{1}\left(d_{T_{1}} \cdot \theta_{1}-d_{T_{2}} \cdot \theta_{2}\right)} .
\end{aligned}
$$

It was expected that these parameters, obtained from internal standards, can then be used with Eq. 4 to obtain the water content $(\theta)$ values across the whole sample domain.

This approach worked for one given sample, regardless of the detailed positioning (extent, lateral location) of the calibration regions within the unaltered clay or cement. However, this was not the case for most of the other samples. In these cases Eq. 5 could not be solved for $\mu_{0}$ and $\beta$, which shows that a single calibration valid for both cement and clay did not exist. Therefore, $\mu_{0}$ and $\beta$ parameters were separately calibrated for cement and clay.

For this purpose, a line in a region of the sample domain far from the interface and with the least alterations was chosen for each material. To improve the statistics, instead of just two-points [22], multiple points were selected (e.g., averaged over $10 \times 10$ pixels) along the calibration line. The transmissivities $A=\ln \left[\frac{T_{d r y}}{T}\right]$ in these calibration regions represent projections of the circular cross sections, obtained for different water thicknesses $d_{w}$. Effective water attenuation coefficients $\mu_{w, \text { eff }}\left(d_{w}\right)$ were then calculated using:

$$
\mu_{w, \mathrm{eff}}\left(d_{w}\right)=\frac{1}{\theta d_{T}} \ln \left[\frac{T_{d r y}}{T}\right]
$$

for each calibration region. In this way, one obtains $\mu_{w \text {,eff }}\left(d_{w}\right)$, i.e., the effective scattering coefficients as a function of the total water thickness in each calibration region (Fig. 2). Finally, the $\mu_{0}$ and $\beta$ valid for the clay or cement sample domain were estimated by fitting the scattered data linearly. The upper and 
lower parts of the sample domain with the smallest sample thickness were excluded from the calibration fit, as they showed generally much larger scatter. That is, only the inner part of the sample, shown by the red rectangle in Fig. 2 . was used for the fit.

As a further problem, it turned out that even though the images were corrected for the variable average neutron inensity (dose), a calibration was only valid for measurements taken around the calibration time, but not for images taken at another time. This is probably related to variations in the beam intensity histograms for images taken at different times or days. Such variations, which were documented (Appendix B), may lead to differences in multiple scattering effects, which then preclude the application of a unique calibration according to our procedure. As a consequence, calibration had to be done for each image. The obtained $\mu_{0}$ and $\beta$ served then as the calibration parameters in Eq. 4 for each measurement time. These parameters account for all the variables affecting the gray values of the image.

The calibration procedure allowed finally deriving the $2 \mathrm{D}$ water content field from the water transmission image. The $2 \mathrm{D}$ water content field was then averaged in $y$ direction, perpendicular to the cylinder axis, in order to present the results as $1 \mathrm{D}$ profiles along the $x$ direction across the material interface. Our samples were always connected to fluid reservoirs on each side, except during the neutron imaging experiments, where the samples were disconnected from the reservoirs but sealed. We thus expect them to be saturated, such that the volumetric water contents represent porosity.

\section{Results and Discussion}

Fig. 3 shows the time series of the obtained volumetric water content profiles across the interfaces of two samples (Table 1). As it can be seen from the general trend of the time-series profiles, the porosity (equal to volumetric water content) on the cement side of the interface tended to increase with increasing reaction time, accompanied by a porosity reduction on the clay side of the 

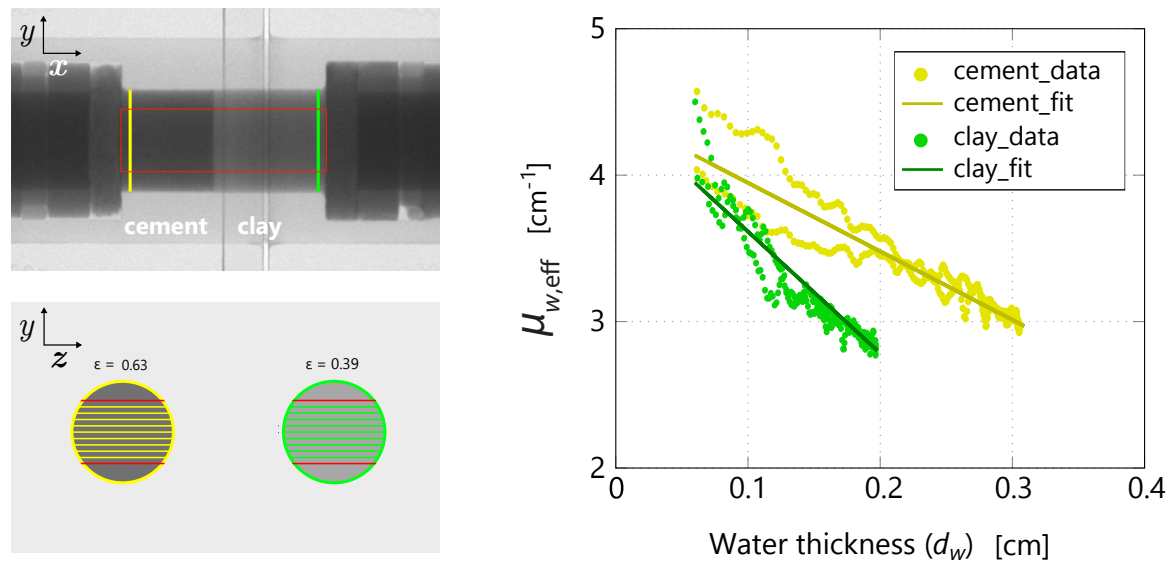

Figure 2: Internal calibration procedure: $\mu_{w, \text { eff }}$ values were derived from transmission values $A$ according to Eq. 6 using the known water content (cement: measured; clay: from bulk dry density) and the total sample thickness along the parallel lines shown in the bottom left figure. A linear fit provided $\mu_{0}$ (intercept) and $\beta$ (slope) for Equation 4 which was used to derive the water content image.

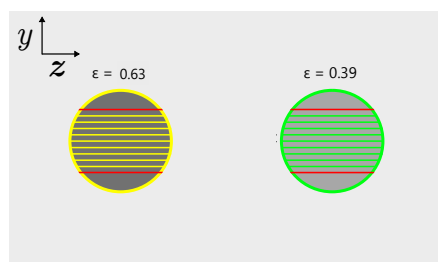

interface. Fig. 4 shows a closer view of the interface for the same samples at select reaction times. Cement and clay zones near the interface changed differently over time, very likely due to dissolution and precipitation reactions. The results are discussed more in detail in the following.

\subsection{Amount and extent of porosity changes}

The porosity in the cement near the interface increased by $\sim 0.05 \mathrm{~m}^{3} \mathrm{~m}^{-3}$ at most, whereas in the clay near the interface it was reduced by up to $\sim 0.12 \mathrm{~m}^{3}$ $\mathrm{m}^{-3}$ (sample C1) and $\sim 0.14 \mathrm{~m}^{3} \mathrm{~m}^{-3}$ (sample C5). Although there is a trend in reduction of clay porosity, a residual porosity clearly larger than zero was preserved at the given spatial resolution of about $30-50 \mu \mathrm{m}$. The extent of the zone where porosity was altered is on the order of $2 \mathrm{~mm}$ on each side of the interface in sample $\mathrm{C} 1$ within 20 months (599 d) of interaction time, and $1 \mathrm{~mm}$ 


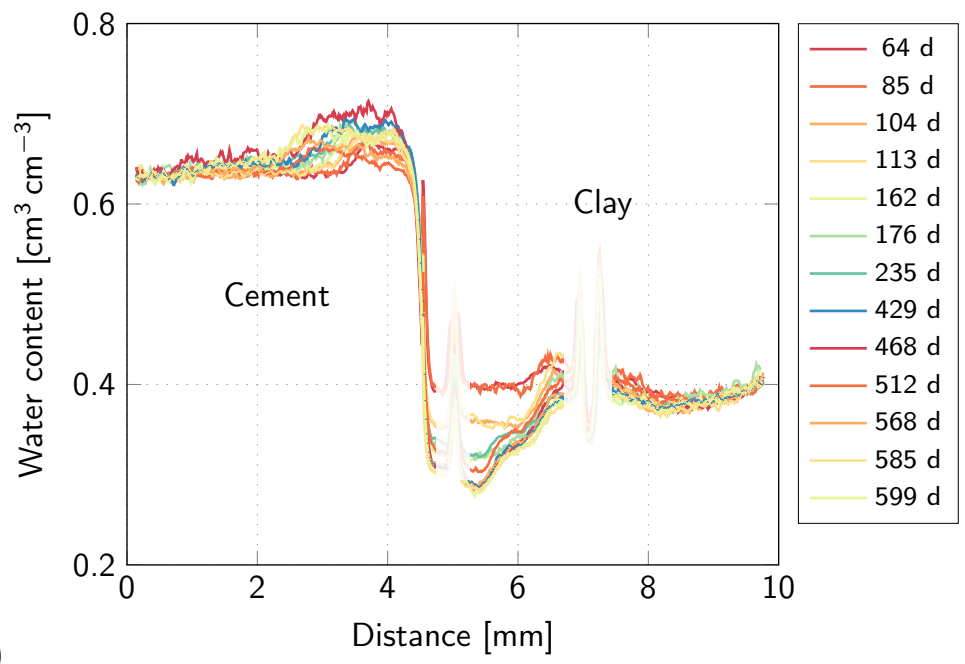

(a)

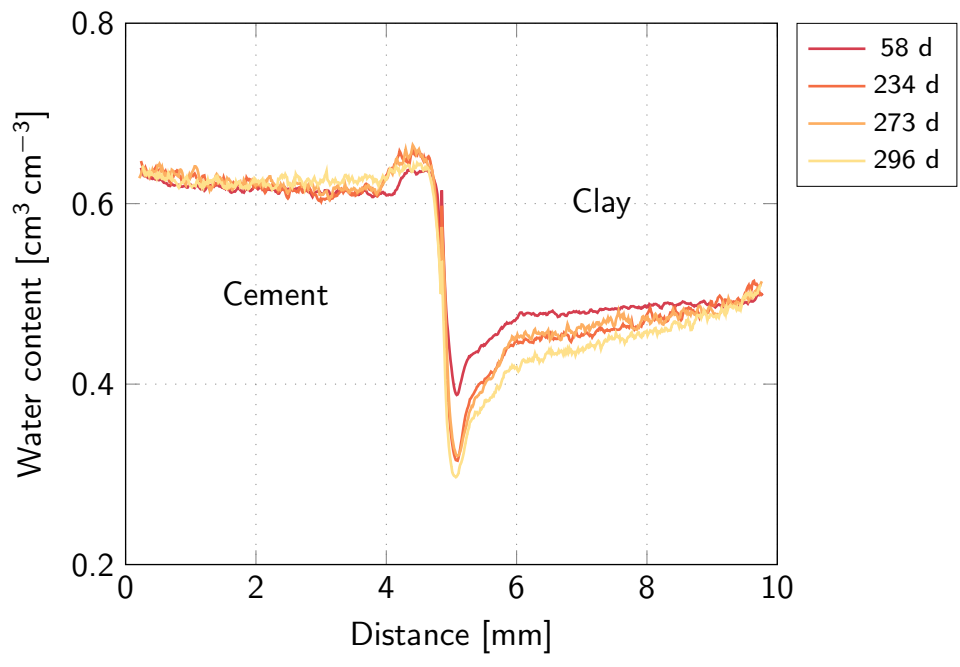

Figure 3: Evolution of profiles of water content with reaction time (in days) across two interface samples (top: sample C1, bottom: sample C5). The regions blanked out for sample $\mathrm{C} 1$ in the top figure are artefacts originating from the joints of the aluminum holder of cell type I; no such artefacts were present anymore with cell type II used for sample C5 in the bottom figure. 

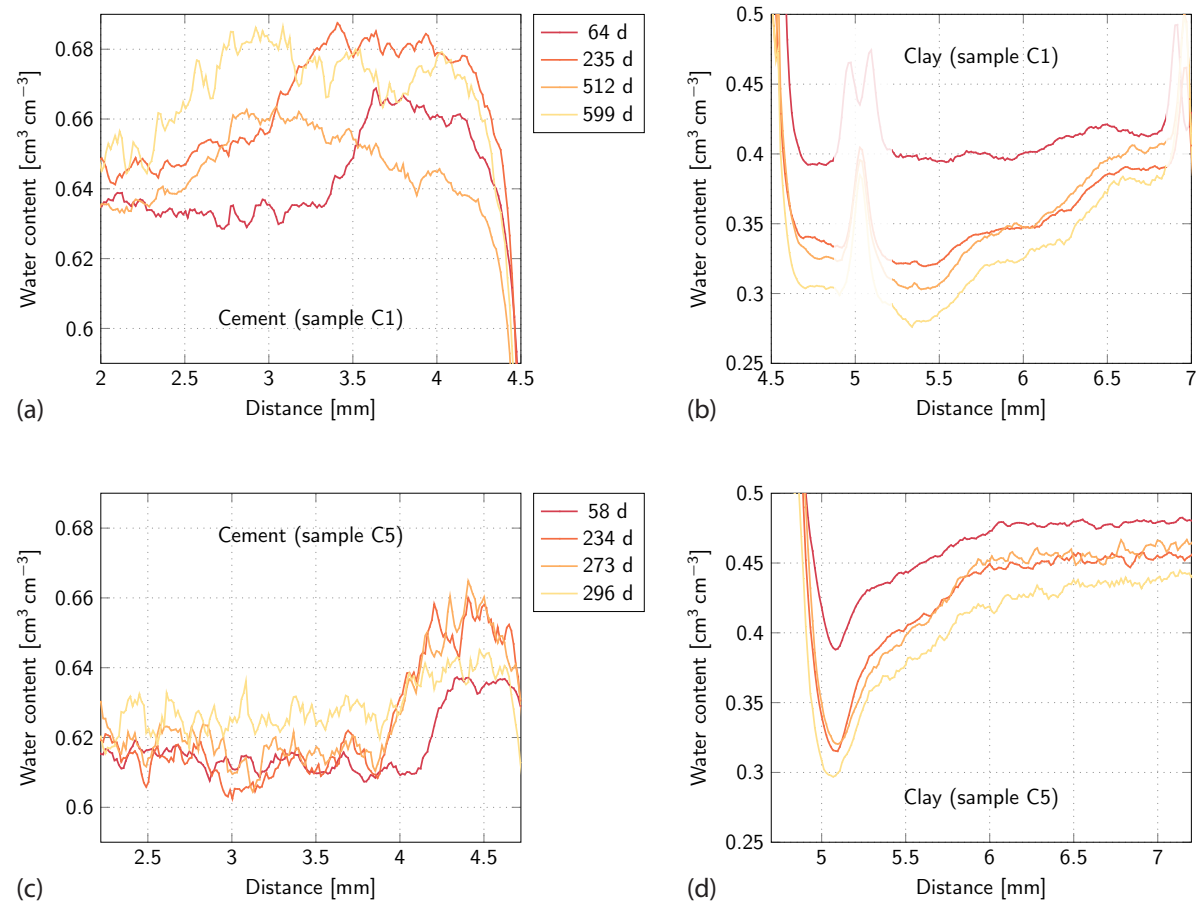

Figure 4: Details of the evolution of the water content profiles across sample C1 (top row) and sample C5 (bottom row) for the cement parts next to the interface (left plots), and for the clay parts next to the interface (right plots).

The two examples represent the typical behavior as observed in most samples, but in one sample no clear porosity changes were detected, and in another sample porosity changes occurred mostly on one side only. It may be that different reactions did not occur at different locations in these samples, but in a mixing zone where both precipitation and dissolution happened. Reactive transport simulations have shown that the extent and location of mineral transformations are very sensitive to various parameters, which may vary locally (microstructural heterogeneities) or from sample to sample in our case. Also, the different patterns could be related to technical limitations of radiographs which flatten and average a possibly heterogeneous 3D structure into a $2 \mathrm{D}$ one. This becomes especially crucial when the contact surface of the cement plug is 
not perfectly flat, e.g., not at an angle of $90^{\circ}$ with respect to the cylinder axis. Depending on the rotational position of the sample during the radiograph, a non-perpendicular interface may not be detected and lead to a mixing of clay and cement properties in the image. A tomography would be required to reveal the $3 \mathrm{D}$ interior of such a sample, but tomography measurements could not be obtained within the limited amount of beam time.

\subsection{Propagation of porosity front in cement and clay}

The water content profiles not only reveal information about the amount and the extent of porosity changes, but also about their temporal evolution. Fig. 5 presents the propagation of the porosity fronts in cement and clay. The location of the front is defined as midpoint of the steep increase or decrease in porosity, and the error bars illustrate the approximate width of this front. The front position on the cement side increased steadily with time up to the last observation date after about $600 \mathrm{~d}$. The relation between the position of the porosity front and the reaction time can be approximately described by:

$$
x \approx \sqrt{D_{a} \cdot t}
$$

where $x$ is the distance between the front and the interface, $D_{a}$ is an apparent diffusion coefficient, and $t$ is the reaction time since interface contact. The apparent diffusion coefficient $D_{a}$ characterizes the approximate transient behavior of the porosity front, but it cannot be related to a retardation coefficient, as in the case of transport of a linearly sorbing tracer. Cement-clay interactions involve strongly non-linear, time-dependent reactions, so using a constant $D_{a}$ for the porosity front evolution on the cement side during the $\sim 600 \mathrm{~d}$ (solid blue line in Fig. 5a) is certainly a strong oversimplification. Detailed reactive transport simulations could give more comprehensive insight into the transient behavior. In any case, if transport parameters $\left(\varepsilon, D_{p}\right)$ on both sides of the interface had varied strongly with time, a change in $D_{a}$ with time should have been observed. Looking at the front propagation within the cement more in detail, it appears that there are two major steps during the $600 \mathrm{~d}$ of this experiment 
(Fig. 5 a - dashed blue line). The porosity front advanced during the first $200 \mathrm{~d}$, then remained at about $1.5 \mathrm{~mm}$ for the next $200 \mathrm{~d}$, before it advanced to $2 \mathrm{~mm}$ and slowed down again. Verifying the validity of this type of behavior needs for instance reactive transport modeling.
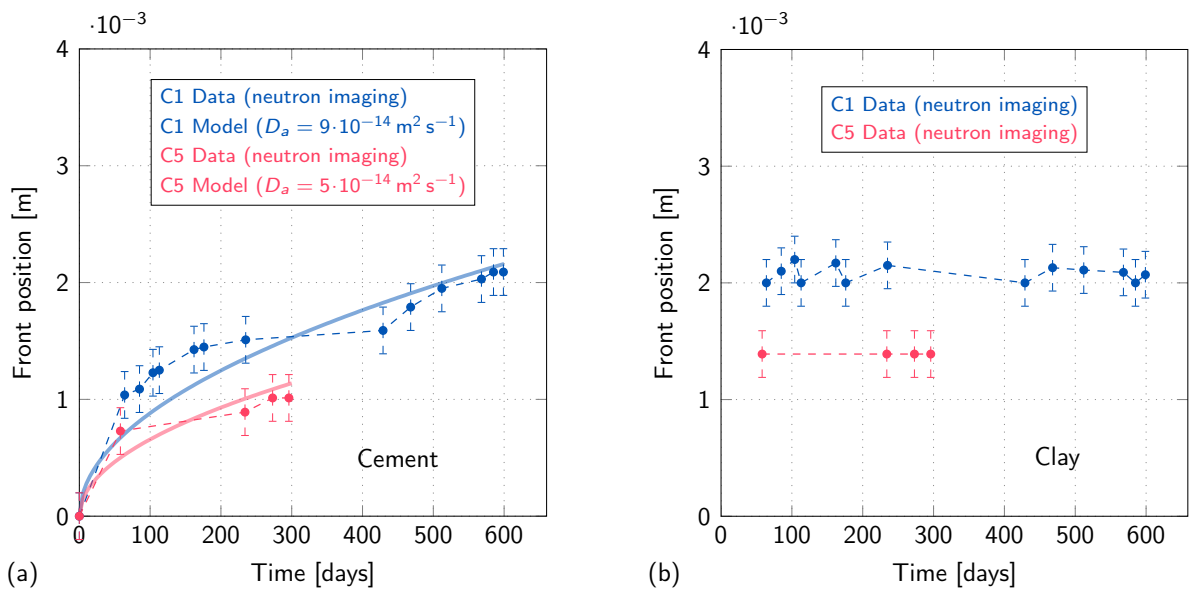

Figure 5: Advancement of the porosity front away from the interface as a function of time in samples C1 and C5. (a) Front position in cement, (b) front position in clay, both estimated as distance of midpoint of steep porosity change to the interface. The model curves in (a) are a strong oversimplification (see text for discussion).

For the clay side (Fig. 5p), the situation is different. The front of reduced porosity in the clay did not advance with the same rate as the front of increased porosity in the cement. The position of the front in the clay appears to be more or less stagnant during the observations. Already at the first measurement after two months $(64 \mathrm{~d})$, the front was located about $2 \mathrm{~mm}$ from the interface. It seems a zone with perturbed porosity had been early created as a result of the interface contact, but this zone did then not further expand significantly with increasing reaction time up to about $600 \mathrm{~d}$, even though reactions within this zone (e.g., porosity reduction) further proceeded.

The porosity front on the cement side moved somewhat slower in sample C5 as compared to sample $\mathrm{C} 1$, and the distance of the porosity front on the clay side is also somewhat smaller in sample C5 compared to sample C1. Sample 
C5 had a lower initial montmorillonite density (and corresponding higher initial montmorillonite porosity), but it is unclear how this could be related to this lower propagation rate. As stated, small differences in local or sample-specific parameters may be responsible for observed quantitative differences between different samples. Reactive transport simulations can help to investigate such subtle sensitivities. In turn, the present data can be very helpful in discriminating between different parameterizations of reactive transport models, especially with respect to the implementation of feedback between porosity and diffusion.

\subsection{Porosity changes as a function of reaction time}

The temporal evolution of porosity values at three different locations within the cement and the clay, respectively, was also derived from the neutron imaging data (Fig. 6). The porosity tended to alter more in areas close to the interface compared to the areas far away from it for both cement and clay. The amount of net porosity change is higher for the clay side compared to the cement side.

The porosity trends in sample $\mathrm{C} 1$ seem to be more or less monotonical in both, cement (increasing) and clay (decreasing), up to about day 450. Then, the trend appears to be inverted on both sides, with a porosity decrease in cement and a porosity increase in clay, up to about day 512. It remains unclear whether these temporary inversions of the trends are real or represent a measurement artefact (e.g., calibration problem). However, the inversions are strongest on the cement side close to the interface, and weaker further away from the interface and on the clay side, which may indicate that they are indeed related to local transport and reaction processes. If real, such changes of trends suggest that different reactions start to dominate at different times. While dissolution and precipitation reactions may occur in parallel, our observation in terms of the porosity, i.e., the sum parameter, just indicate that on the cement side, dissolution mostly — with the exception around day 500 — outweighs precipitation during the experiment, whereas on the clay side, precipitation mostly outweighs dissolution. 

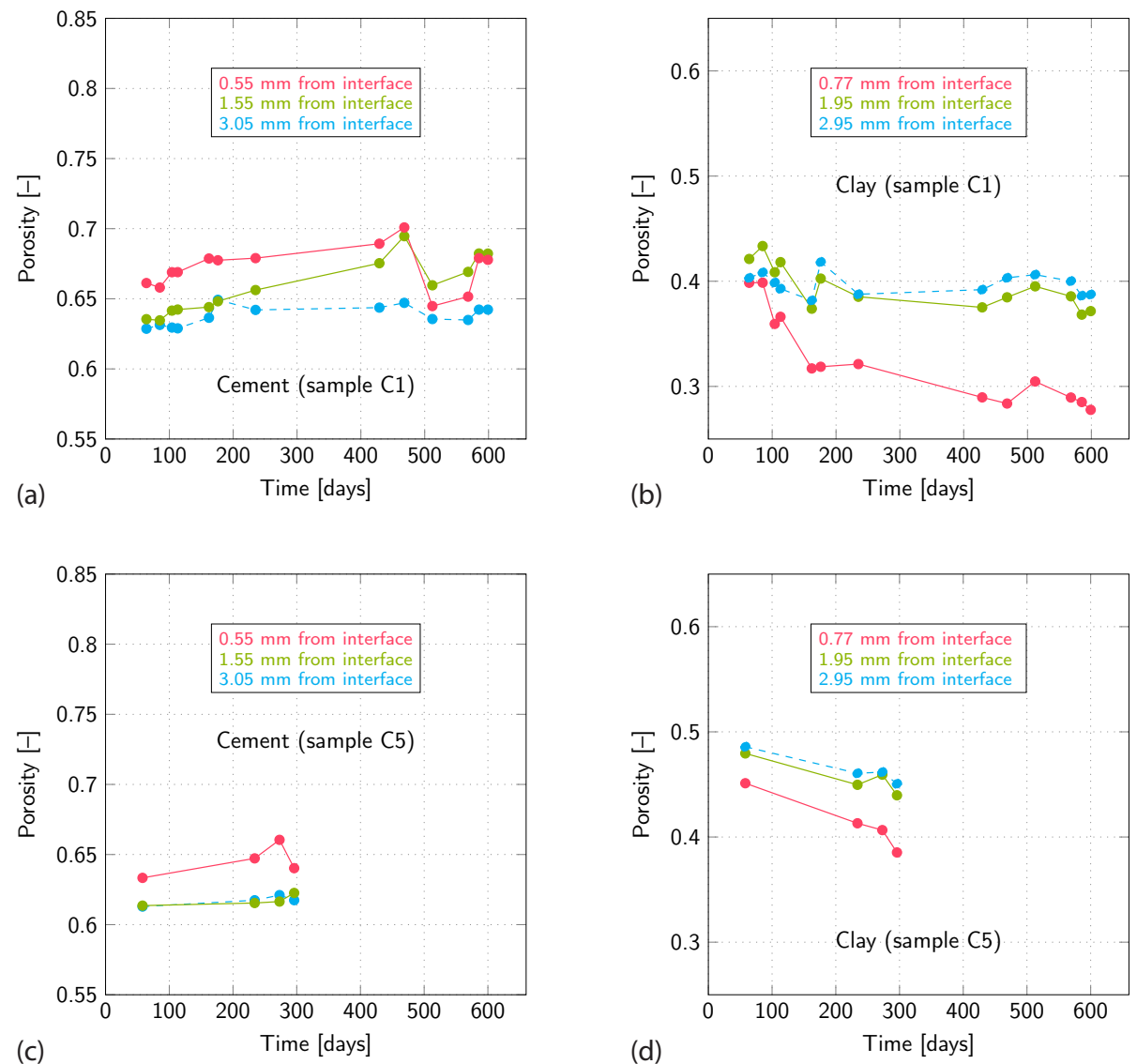

Figure 6: Porosity changes as a function of reaction time at different positions in cement (left plots) and clay (right plots) for samples C1 (top row) and C5 (bottom row).

\subsection{Significance of derived porosity data}

As mentioned above in subsection 3.1. not all our experimental results are identical and there is some variability in the observations between different samples, with some samples exhibiting less reactions. The reasons are unknown, but the differences may be related to small parameter variations between the different samples. Anyway, the data shown here represent typical observations.

The materials chosen, especially in the case of the clay, are simplified analogs compared to those foreseen in natural or engineered barriers or used in field experiments, as for instance in the CI experiment in the Mont Terri rock laboratory 
[2. This allowed us to focus on the most important interaction processes at the interface and also to provide simpler, better constrained initial conditions for numerical codes. The duration of the reaction between the selected cement and clay materials and the size of the samples (comparably small) were also different from other works on this topic. Although based on small samples, our method presented here has the advantage that it can provide the time and space dependence of porosity changes, in contrast to all methods that require a destructive sampling. Furthermore, it is possible to create and investigate many different samples with reasonable effort.

We are not aware of other studies that provide the porosity evolution at cement-clay interfaces as a function of time and space. In any case, the trends observed during the present study are qualitatively in agreement with observations from other in situ and laboratory experiments. For example, there is a similarity between the findings from this study and the works of Read et al. [1, Gaboreau et al. 7], and Bartier et al. 9]. Fig. 7] shows how the porosity determined from petrophysical measurements varied as a function of distance from a cement-argillite contact in the Tournemire URL after 15 years of interaction [7. From their measurements, these authors reported "a clogging of the porosity in the clay-rock while the porosity increases in the cement". The porosity evolution was shown to extend to about a centimeter on both sides of the interface, but "heterogeneously distributed in space as a function of the fissure network and interface geometries".

The observed changes in porosity are most likely related to mineral alterations. The porosity increase on the cement side is probably linked to the dissolution of portlandite [5], whereas the nature of the precipitating phase on the clay side is yet unclear at present. Besides precipitation and dissolution reactions, the interaction with cement also triggers modifications of the exchanger population of a clay [e.g., 35, 36], with $\mathrm{Na}$ being replaced by $\mathrm{K}$ and Ca. Such modifications, which typically propagate more quickly as compared to the front(s) of dissolution or precipitation reactions, can affect the interlayer distances and thus the local distribution of water between different pore en- 


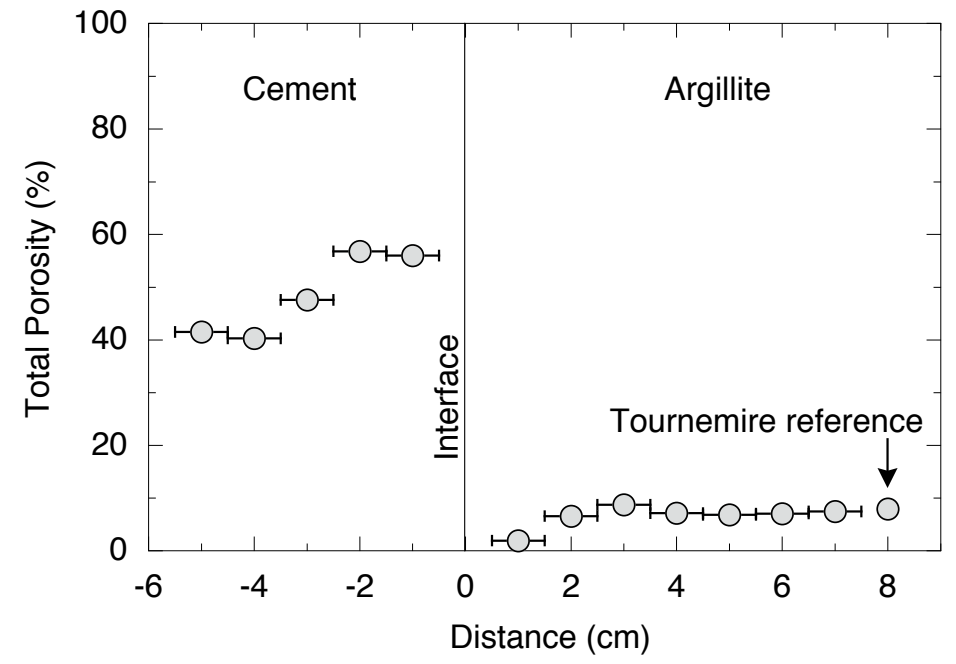

Figure 7: Total connected porosity at a cement-clay interface after 15 months of interaction (modified from [7]).

vironments (e.g., interlayer, interparticle). But for our confined samples, this redistribution of the pore water is expected to have no or only a weak effect on the total porosity.

\section{Conclusions and outlook}

In this paper we presented time-series results of water content profiles across several evolving cement-clay interfaces. The water contents, which served as proxy for porosity, were evaluated from neutron radiographs with a new methodology. The present work showed the need to obtain a separate calibration measurement for the neutron images for each material at every measurement time, especially for investigations spanning long periods of time. Such a need for internal standard imposes some limits to the applicability of the method to evolving samples. First, a suited internal calibration region has to be available for each material. Second, mineral changes within each material should remain comparably small; otherwise, the calibration may no longer be adequate. We used the unaltered cement or clay material, far away from the interface, as internal cali- 
bration region, and furthermore applied an approximate correction for multiple scattering effects.

The finally observed porosity trends appear reasonable both qualitatively and quantitatively. To cross check the validity of our observations, a $\mathrm{D}_{2} \mathrm{O}$ diffusion experiment was subsequently planned and performed on several interface samples. This is the topic of a forthcoming publication, but, without going into details, we expect that the derived porosity changes can be confirmed by the $\mathrm{D}_{2} \mathrm{O}$ exchange experiment. Also, a new scattering correction method was developed very recently, which will be applied in future experiments to improve the estimation accuracy [37, 38. Neutron imaging, which can be combined with complimentary X-ray tomography in the future, offers thus unique possibilities to non-destructively determine porosity changes as a function of time in reacting cement or rock samples.

The time-series results revealed a clear evolution of water content or porosity close to the interface. An increase in the porosity on the cement side of the interface accompanied by a reduction of porosity on the clay side was observed. These trends are broadly in agreement with observations from in-situ studies. The porosity increase on the cement side is very likely related to portlandite dissolution [5]. The nature of the precipitating phase(s) on the clay side has still to be studied. The likely modification in the exchanger population of the clay (from $\mathrm{Na}$ to $\mathrm{K}, \mathrm{Ca},[$ e.g., 35, 36]) is expected to have only a minor effect on the total porosity in our confined samples.

The ultimate goal of this work was to provide quantitative porosity data at reacting cement-clay interfaces as a function of time, in order to serve the further development of reactive transport models, especially with respect to the feedback between porosity and diffusion. Porosity is at the same time a key parameter for, and a key outcome of, reactive transport. The obtained porosity data set, together with forthcoming chemical analyses of the reacted zones, can be examined using reactive transport codes. The comparably simple initial mineralogical composition of our system certainly facilitates the further interpretation and modeling of the observations. Based on the comparison of 
experimental data and modeling results, one may have to adapt existing or introduce new model parameters and feedback mechanisms, all with the aim to eventually better simulate the evolution of cement-clay interfaces in waste repositories. The small-scale experimental observations obtained in this study may thus serve as benchmark data that assist in increasing the confidence in predictions of the long-term stability of cement and clay interfaces.

\section{Acknowledgements}

Technical support by the ICON beamline facility technicians is kindly acknowledged. We thank Erich Wieland and Dominik Kunz (PSI) for providing the hardened cement paste. Partial financial support provided by the Swiss national cooperative for the disposal of radioactive waste (Nagra) is gratefully acknowledged.

\section{References}

[1] D. Read, F. P. Glasser, C. Ayora, M. T. Guardiola, A. Sneyers, Mineralogical and microstructural changes accompanying the interaction of Boom Clay with ordinary Portland cement, Advances in Cement Research 13 (2001) 175-183. doi 10.1680/adcr.2001.13.4.175

[2] A. Jenni, U. Mäder, C. Lerouge, S. Gaboreau, B. Schwyn, In situ interaction between different concretes and Opalinus Clay, Physics and Chemistry of the Earth 70-71 (2014) 71-83. doi 10.1016/j.pce.2013.11.004

[3] A. Dauzères, G. Achiedo, D. Nied, E. Bernard, S. Alahrache, B. Lothenbach, Magnesium perturbation in low-ph concretes placed in clayey environment - solid characterizations and modeling, Cement and Concrete Research 79 (2016) 137-150.

[4] U. Mäder, A. Jenni, C. Lerouge, S. Gaboreau, S. Miyoshi, Y. Kimura, V. Cloet, M. Fukaya, F. Claret, T. Otake, M. Shibata, B. Lothenbach, 5year chemico-physical evolution of concrete-claystone interfaces, Mont Terri 
rock laboratory (Switzerland), Swiss Journal of Geosciences 110 (2017) 307-327. doi $10.1007 / \mathrm{s} 00015-016-0240-5$.

[5] M. Cruz Alonso, J. L. G. Calvo, J. Cuevas, M. J. Turrero, R. Fernández, E. Torres, A. I. Ruiz, Interaction processes at the concrete-bentonite interface after 13 years of febex-plug operation. part i: Concrete alteration, Physics and Chemistry of the Earth 99 (2017) 38-48. doi 10.1016/j.pce. 2017.03 .008

[6] R. Fernández, E. Torres, A. I. Ruiz, J. Cuevas, M. C. Alonso, J. L. G. Calvo, E. Rodríguez, M. J. Turrero, Interaction processes at the concretebentonite interface after 13 years of febex-plug operation. part ii: Bentonite contact, Physics and Chemistry of the Earth 99 (2017) 49-63. doi 10.1016/ j.pce.2017.01.009

[7] S. Gaboreau, D. Prêt, E. Tinseau, F. Claret, D. Pellegrini, D. Stammose, 15 years of in situ cement-argillite interaction from Tournemire URL: Characterisation of the multi-scale spatial heterogeneities of pore space evolution, Applied Geochemistry 26 (2011) 2159-2171. doi:10.1016/j.apgeochem. 2011.07 .013

[8] I. Techer, D. Bartier, P. Boulvais, E. Tinseau, K. Suchorski, J. Cabrera, A. Dauzères, Tracing interactions between natural argillites and hyperalkaline fluids from engineered cement paste and concrete: Chemical and isotopic monitoring of a 15-years old deep-disposal analogue, Applied Geochemistry 27 (2012) 1384-1402. doi:10.1016/j.apgeochem.2011.08.013.

[9] D. Bartier, I. Techer, A. Dauzères, P. Boulvais, M.-M. M. Blanc-Valleron, J. Cabrera, In situ investigations and reactive transport modelling of cement paste/argillite interactions in a saturated context and outside an excavated disturbed zone, Applied Geochemistry 31 (2013) 94-108. doi $10.1016 / \mathrm{j}$.apgeochem.2012.12.009.

[10] P. Lalan, A. Dauzeres, L. De Windt, D. Bartier, J. Sammaljarvi, J. D. 
Barnichon, I. Techer, V. Detilleux, Impact of a 70 degrees c temperature on an ordinary portland cement paste/claystone interface: An in situ experiment, Cement and Concrete Research 83 (2016) 164-178. doi $10.1016 /$ j.cemconres.2016.02.001.

[11] P. Lalan, A. Dauzeres, L. De Windt, J. Sammaljarvi, D. Bartier, I. Techer, V. Detilleux, M. Siitari-Kauppi, Mineralogical and microstructural evolution of portland cement paste/argillite interfaces at 70 degrees $\mathrm{c}$ - considerations for diffusion and porosity properties, Cement and Concrete Research 115 (2019) 414-425. doi $10.1016 /$ j . cemconres. 2018.09.018.

[12] L. H. J. Martin, A. Leemann, A. E. Milodowski, U. K. Mäder, B. Münch, N. Giroud, A natural cement analogue study to understand the longterm behaviour of cements in nuclear waste repositories: Maqarin (Jordan), Applied Geochemistry 71 (2016) 20-34. doi 10.1016/j.apgeochem.2016. 05.009.

[13] G. Kosakowski, U. Berner, The evolution of clay rock/cement interfaces in a cementitious repository for low- and intermediate level radioactive waste, Physics and Chemistry of the Earth 64 (2013) 65-86. doi 10.1016/j.pce. 2013.01 .003

[14] D. Traber, U. K. Mäder, Reactive Transport Modelling of the Diffusive Interaction Between Opalinus Clay and Concrete, Nagra Unpublished Report, 2012.

[15] N. C. M. Marty, C. Tournassat, A. Burnol, E. Giffaut, E. C. Gaucher, Influence of reaction kinetics and mesh refinement on the numerical modelling of concrete/clay interactions, Journal of Hydrology 364 (2009) 58-72. doi $10.1016 / j \cdot$ jhydrol.2008.10.013.

[16] N. C. M. Marty, I. Munier, E. C. Gaucher, C. Tournassat, S. Gaboreau, C. Q. Vong, E. Giffaut, B. Cochepin, F. Claret, Simulation of Cement/Clay Interactions: Feedback on the Increasing Complexity of 
Modelling Strategies, Transport in Porous Media 104 (2014) 385-405. doi $10.1007 / \mathrm{s} 11242-014-0340-5$.

[17] L. Döhring, S. Görlich, W., Rüttener, R. Schwerzmann, Herstellung von homogenen Zementsteinen mit hoher hydraulischer Permeabilität, NAGRA unpublished report NIB 94-29 (1994).

[18] E. Wieland, J. Tits, P. Spieler, J. Dobler, Interaction of Eu(III) and Th(IV) with sulfate-resisting portland cement, MRS Proceedings 506 (1998) 573. doi $10.1557 /$ PROC-506-573.

[19] J. Tits, a. Jakob, E. Wieland, P. Spieler, Diffusion of tritiated water and $22 \mathrm{Na}+$ through non-degraded hardened cement pastes., Journal of contaminant hydrology 61 (2003) 45-62. doi 10.1016/S0169-7722(02)00112-2.

[20] B. Lothenbach, E. Wieland, A thermodynamic approach to the hydration of sulphate-resisting Portland cement, Waste Management 26 (2006) 706719. doi $10.1016 /$ j.wasman.2006.01.023.

[21] M. A. Glaus, S. Frick, R. Rossé, L. R. V. Loon, Comparative study of tracer diffusion of HTO, 22Na+ and 36Cl- in compacted kaolinite, illite and montmorillonite, Geochimica et Cosmochimica Acta 74 (2010) 19992010. doi $10.1016 /$ j.gca.2010.01.010.

[22] A. Shafizadeh, T. Gimmi, L. Van Loon, A. Kaestner, E. Lehmann, U. Maeder, S. Churakov, Quantification of water content across a cementclay interface using high resolution neutron radiography, Physics Procedia 69 (2015) 516-523. doi $10.1016 / \mathrm{j}$. phpro.2015.07.073.

[23] D. A. Kulik, T. Wagner, S. V. Dmytrieva, G. Kosakowski, F. F. Hingerl, K. V. Chudnenko, U. R. Berner, GEM-Selektor geochemical modeling package: Revised algorithm and GEMS3K numerical kernel for coupled simulation codes, Computational Geosciences 17 (2013) 1-24. doi 10.1007/ s10596-012-9310-6. 
[24] R. Hassanein, H. O. Meyer, A. Carminati, M. Estermann, E. Lehmann, P. Vontobel, Investigation of water imbibition in porous stone by thermal neutron radiography, Journal of Physics D: Applied Physics 39 (2006) 4284-4291. doi:10.1088/0022-3727/39/19/023.

[25] M. Kang, H. Z. Bilheux, S. Voisin, C. L. Cheng, E. Perfect, J. Horita, J. M. Warren, Water calibration measurements for neutron radiography: Application to water content quantification in porous media, Nuclear Instruments and Methods in Physics Research, Section A: Accelerators, Spectrometers, Detectors and Associated Equipment 708 (2013) 24-31. doi $10.1016 / j . n i m a .2012 .12 .112$.

[26] A. Carminati, A. Kaestner, R. Hassanein, O. Ippisch, P. Vontobel, H. Flühler, Infiltration through series of soil aggregates: Neutron radiography and modeling, Advances in Water Resources 30 (2007) 1168-1178. doi $10.1016 / \mathrm{j}$.advwatres.2006.10.006.

[27] S. Lal, L. D. Poulikakos, M. Sedighi Gilani, I. Jerjen, P. Vontobel, M. N. Partl, J. C. Carmeliet, D. Derome, Investigation of Water Uptake in Porous Asphalt Concrete Using Neutron Radiography, Transport in Porous Media 105 (2014) 431-450. doi 10.1007/s11242-014-0376-6.

[28] A. Lagorce-Tachon, T. Karbowiak, C. Loupiac, A. Gaudry, F. Ott, C. AlbaSimionesco, R. D. Gougeon, V. Alcantara, D. Mannes, A. Kaestner, E. Lehmann, J.-P. Bellat, The cork viewed from the inside, Journal of Food Engineering 149 (2015) 214-221. doi 10.1016/j.jfoodeng.2014.10.023.

[29] B. Weber, M. Wyrzykowski, M. Griffa, S. Carl, E. Lehmann, P. Lura, Neutron radiography of heated high-performance mortar, MATEC Web of Conferences 6 (2013) 03004. doi 10.1051/matecconf/20130603004

[30] E. Perfect, C. L. Cheng, M. Kang, H. Z. Bilheux, J. M. Lamanna, M. J. Gragg, D. M. Wright, Neutron imaging of hydrogen-rich fluids in geomaterials and engineered porous media: A review, Earth-Science Reviews 129 (2014) 120-135. doi 10.1016/j . earscirev.2013.11.012. 
[31] P. Trtik, B. Münch, W. Weiss, A. Kaestner, I. Jerjen, L. Josic, E. Lehmann, P. Lura, Release of internal curing water from lightweight aggregates in cement paste investigated by neutron and X-ray tomography, Nuclear Instruments and Methods in Physics Research Section A: Accelerators, Spectrometers, Detectors and Associated Equipment 651 (2011) 244-249. doi: $10.1016 /$ j.nima.2011.02.012

[32] P. Lehmann, D. Or, Evaporation and capillary coupling across vertical textural contrasts in porous media, Physical Review E - Statistical, Nonlinear, and Soft Matter Physics 80 (2009) 1-13. doi:10.1103/PhysRevE. 80.046318 .

[33] A. Kaestner, S. Hartmann, G. Kühne, G. Frei, C. Grünzweig, L. Josic, F. Schmid, E. Lehmann, The ICON beamline - A facility for cold neutron imaging at SINQ, Nuclear Instruments and Methods in Physics Research Section A: Accelerators, Spectrometers, Detectors and Associated Equipment 659 (2011) 387-393. doi:10.1016/j.nima.2011.08.022.

[34] R. K. Hassanein, Correction methods for the quantitative evaluation of thermal neutron tomography, Ph.D. thesis, ETH No. 16809, 2006. URL: http://e-collection.library.ethz.ch/view/eth:29045 doi:10.3929/ethz-a-005273682.

[35] C. Watson, K. Hane, D. Savage, S. Benbow, J. Cuevas, R. Fernandez, Reaction and diffusion of cementitious water in bentonite: Results of 'blind' modelling, Applied Clay Science 45 (2009) 54-69. doi 10.1016/j.clay. 2009.03.007.

[36] R. Fernández, U. K. Mader, M. Rodríguez, R. V. de la Villa, J. Cuevas, Alteration of compacted bentonite by diffusion of highly alkaline solutions, European Journal of Mineralogy 21 (2009) 725-735. doi 10.1127/ 0935-1221/2009/0021-1947.

[37] P. Boillat, C. Carminati, F. Schmid, C. Grünzweig, J. Hovind, A. Kaestner, D. Mannes, M. Morgano, M. Siegwart, P. Trtik, P. Vontobel, E. Lehmann, 
Chasing quantitative biases in neutron imaging with scintillator-camera detectors: a practical method with black body grids, Optics Express 26 (2018) 15769. doi $10.1364 /$ oe.26.015769

[38] C. Carminati, P. Boillat, F. Schmid, P. Vontobel, J. Hovind, M. Morgano, M. Raventos, M. Siegwart, D. Mannes, C. Gruenzweig, P. Trtik, E. Lehmann, M. Strobl, A. Kaestner, Implementation and assessment of the black body bias correction in quantitative neutron imaging, PLOS ONE 14 (2019) e0210300. doi 10.1371/journal.pone.0210300. 
Appendix A

579 The transmission values of a cylindrical cell fully filled with water are de${ }_{580}$ creasing with increasing water thickness (Fig. A.1 a,b). Scattering effects lead to decrease of the effective attenuation coefficient $\mu_{w}$ with increasing sample thickness (Fig. A.1k,d). This suggests using a linear calibration function for the attenuation coefficient of water in order to derive correct water contents. Such a calibration procedure was used in the present work. 

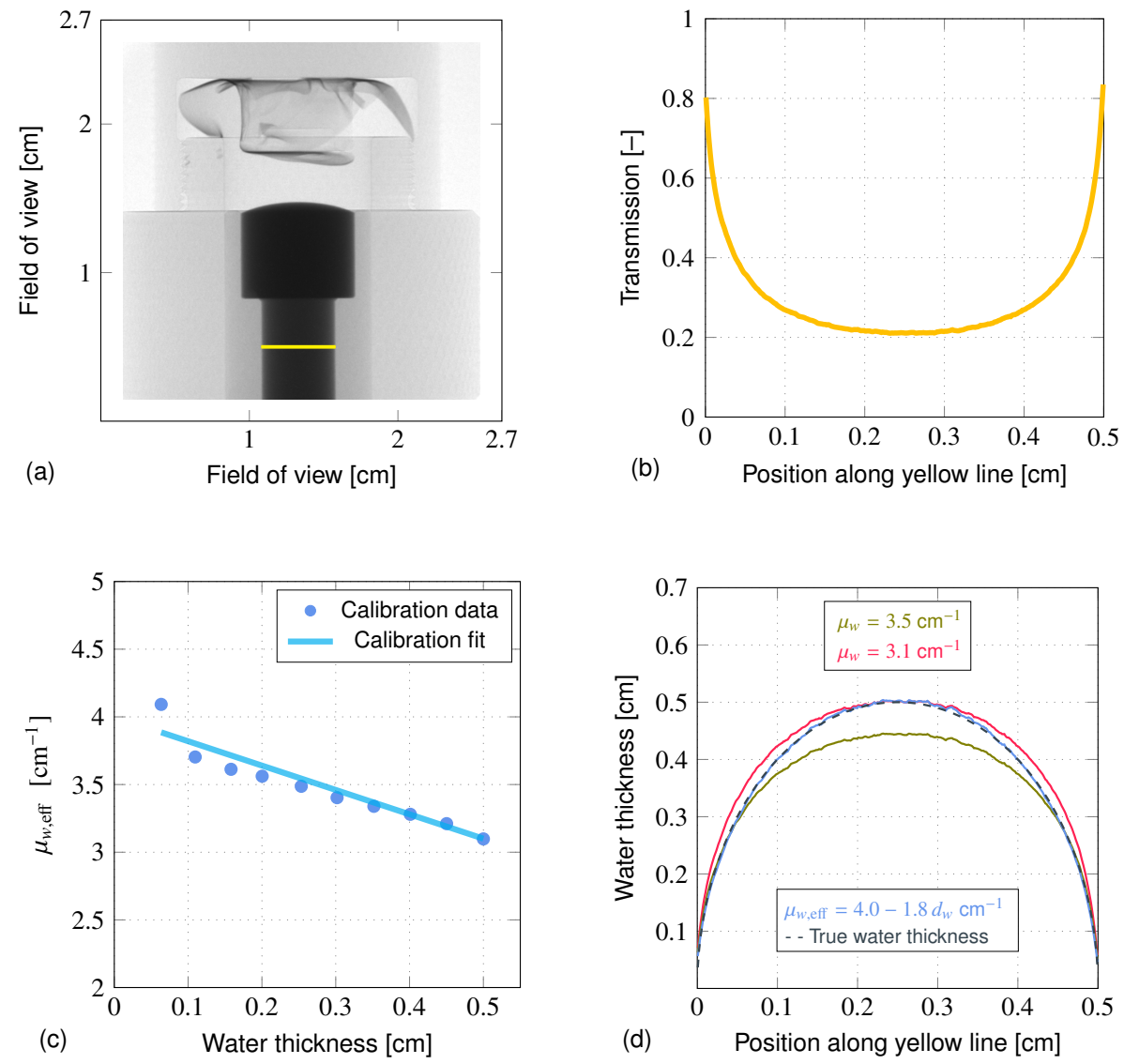

Figure A.1: Transmission values and attenuation coefficients obtained for the cylindrical sample cell (cell type II) filled with water. (a) Transmission image, with the yellow line indicating the evaluated cross section of the radial cell. (b) Transmission values along the yellow line. (c) Water attenuation coefficients as a function of true water thicknesses along the yellow line. (d) Comparison of true water thickness (dashed line) along the yellow line, and water thickness calculated by using constant attenuation coefficients $\mu_{w}$ of 3.5 and $3.1 \mathrm{~cm}^{-1}$, or the $\mu_{w, \text { eff }}$ that varies linearly with water thickness according to the calibration fit in (c). 


\section{Appendix B}

Fig. B.1 shows histograms of several open beam intensities recorded over a period of 3 years. The values of 16-bit images range between 0 and 65,535 $\left(2^{16}-1\right)$, but our open beam images had a smaller range with values between 0 and 10,500. The intensities were binned in intervals of 100. The histogram plots show clearly that not only the recorded mean intensity of the beam varies with time, but also the intensity distribution. It is likely that several parameters of the beamline setup, including the incident neutron beam intensity, varied over the 3 year observation time. The variations can affect the amount of neutrons scattered from the sample. The lowest gray values in the histograms indicate a probability of the presence of clearly lower energy neutrons in the poly-energetic beam. Low energy neutrons have a higher scattering probability when passing through the sample. Accordingly, any shifts or distortions in the energy spectrum will affect the mean attenuation coefficient of the water in the sample, as well as the probability of multiple scattering. The partly variable shape of the histograms thus demonstrates that a simple dose window correction procedure is not able to fully account for intensity variations. The most important influence of such variations is their fingerprint on the energy dependent values of the water attenuation coefficient. This highlights the necessity of an experiment-specific time-dependent calibration procedure. 


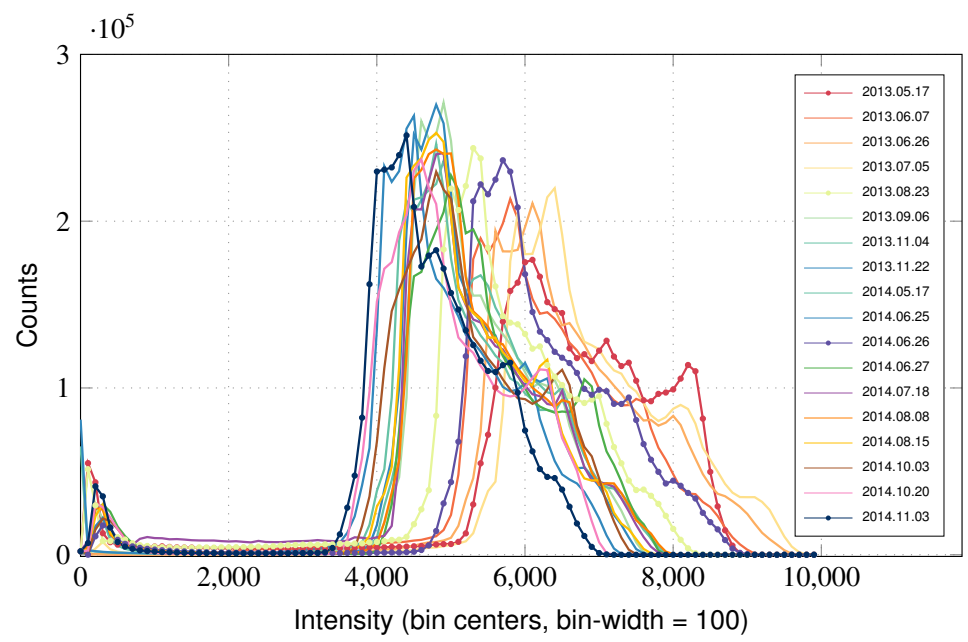

Figure B.1: Histograms of the open beam intensities over a period of 3 years as an indication of setup imposed deviations (beam energy, detector efficiency and camera system variations). The histograms present the frequencies of binned gray values. For our setup intensities of the gray values were between 0 and 10,500 (generally between 0 and 65,535 for a 16-bit image). The intensities were binned in intervals of 100, an arbitrary bin-width. The figure shows the counts in each interval for each open beam image. 
Appendix C

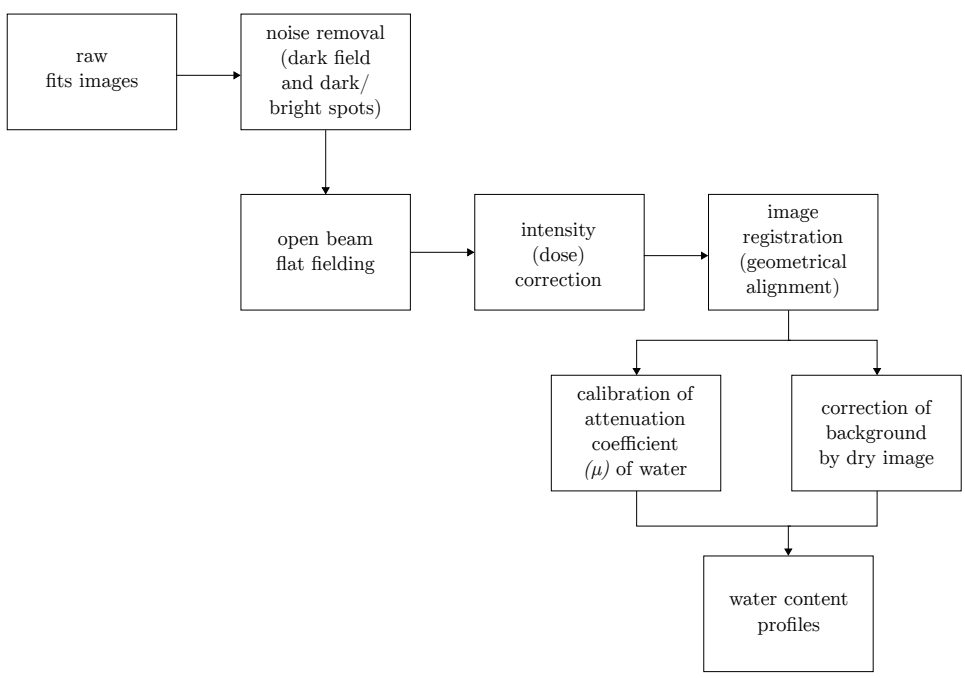

Figure C.1: Image processing sequence applied on the raw data to obtain the water content in the interface samples. 